\title{
12. REFLECTIVITY MODELING OF THE LAYER 3 GABBROIC SEQUENCE DRILLED AT THE ATLANTIS II FRACTURE ZONE ${ }^{1}$
}

\author{
Gerardo J. Iturrino ${ }^{2,3}$ and Nikolas I. Christensen ${ }^{2}$
}

\begin{abstract}
On the basis of visual core descriptions, 43 layers of varying thickness, diagnostic mineralogy, and deformation textures were identified within the six main lithologic units drilled at Hole 735B. Compressional-wave velocities and densities of drill-core samples measured in the laboratory at selected confining pressures were used for calculating normal-incidence synthetic reflection seismograms. The synthetic seismograms show that significant reflections are produced at the interfaces between gabbroic layers of diverse chemical composition. Microcrack porosity reduces the amplitude of reflections at low pressures. The amount of $\mathrm{SiO}_{2}$ and $\mathrm{Fe}_{2} \mathrm{O}_{3}$ present has an inverse relationship with compressional-wave velocities, and these constituents are major factors controlling the reflectivity at higher pressures. In addition, variations in anisotropy $(<10 \%)$ within fairly homogeneous sections may also produce significant reflections. However, anisotropy probably is of secondary importance for determining the reflectivity of the gabbroic sequence drilled at Hole 735B.
\end{abstract}

\section{INTRODUCTION}

Since the 1960 s, the composition of the oceanic crust has been a subject of great interest due largely to the general acceptance of the concepts of seafloor spreading and plate tectonics. Early research (e.g., Ewing and Ewing, 1959; Raitt, 1956; Le Pichon et al., 1965; Talwani et al., 1965; Shor et al., 1969) described the structure of the oceanic basins using seismic methods, as well as potential field techniques. In the last two decades, DSDP and ODP recoveries allowed for more accurate interpretations of these and other upper crustal marine geophysical data. The $500 \mathrm{~m}$ of gabbroic rock recovered from Hole 735B on the Atlantis II Fracture Zone provides scientists the opportunity of studying the parameters controlling the reflections and refractions observed in lower crustal marine seismic surveys.

The purpose of this study is to model the reflectivity of oceanic layer 3, where in-situ pressures generally vary between 100 and $200 \mathrm{MPa}$. At shallow crustal depths, seismic properties are strongly influenced by pervasive fractures and possible rubble zones (Hess, 1962; Hyndman and Drury, 1976; Houtz and Ewing, 1976), whereas lower crustal regions are likely to be fracture free (Christensen and Salisbury, 1975). Thus, for our seismic modeling of lower crustal reflectivity, we have selected laboratory data for velocities and densities at appropriate confining pressures (Iturrino et al., this volume), rather than the sonic velocity log obtained form Hole $735 \mathrm{~B}$ at relatively shallow crustal depths (Fig. 1A).

\section{SYNTHETIC REFLECTION SEISMOGRAMS OF HOLE 735B}

A total of 43 distinctive layers were identified within the six lithologic units of Hole 735B from thin-section observations and visual core descriptions (Robinson, Von Herzen, et al., 1989). Compressional-wave velocities measured using the pulse transmission method (Birch, 1960; Christensen, 1965, $1985)$ were assigned to each layer for a range of pressures (10,

\footnotetext{
${ }^{1}$ Von Herzen, R. P., Robinson, P. T., et al., 1991. Proc. ODP, Sci. Results, 118: College Station, TX (Ocean Drilling Program).

${ }^{2}$ Rock Physics Laboratory, Department of Earth and Atmospheric Sciences, Purdue Univ., West Lafayette, IN 47907, U.S.A.

${ }^{3}$ RSMAS/MMG, 4600 Rickenbacker Causeway, Miami, FL 33149, U.S.A.
}

100 , and $200 \mathrm{MPa}$ ) and assuming horizontal layering and vertical incidence. Details of the measurement technique, measurement errors, and sample preparation are given in Iturrino et al. (this volume).

The synthetic reflection seismograms presented here simulate the propagation of normal-incidence acoustic waves through a layered media (Robinson and Treitel, 1977). The seismic response is controlled by the acoustic impedance $(Z)$, a product of the velocities and densities of individual layers. The reflection coefficient $(R)$, determined from the acoustic impedance contrasts between two layers is given by

$$
R_{12}=\frac{Z_{2}-Z_{1}}{Z_{2}+Z_{1}}
$$

Hence, a positive reflection coefficient is produced by an increase in acoustic impedance with depth, while a negative reflection coefficient results from a decrease in the same parameter.

The percentage of energy not reflected continues to propagate downward. This portion of energy is accounted for by the transmission coefficient. The sum of the reflection and transmission coefficients equals one; thus, by knowing the reflection coefficient, the amount of energy transmitted can be determined. For the synthetic seismograms presented here, transmission losses at interface boundaries were accounted for. However, attenuation, scattering, and dispersion were not considered. In addition, the calculation assumed no multiply reflected energy, and the signal-to-noise ratio was considered to be infinite.

\section{RESULTS AND DISCUSSION}

For refraction and reflection studies of the oceanic crust, the frequencies of air-gun and explosive sources generally range from 5 to $30 \mathrm{~Hz}$. Synthetic seismograms of the section recovered at Hole 735B were calculated for velocities measured at varying confining pressures using $25-\mathrm{Hz}$ Ricker wavelets (Ricker, 1953) and shown in Figures 1 through 3. Similar results were obtained using $20-$ and $30-\mathrm{Hz}$ sources, suggesting that for these models, the seismic response over this range is not frequency-dependant. The wavelength of a 


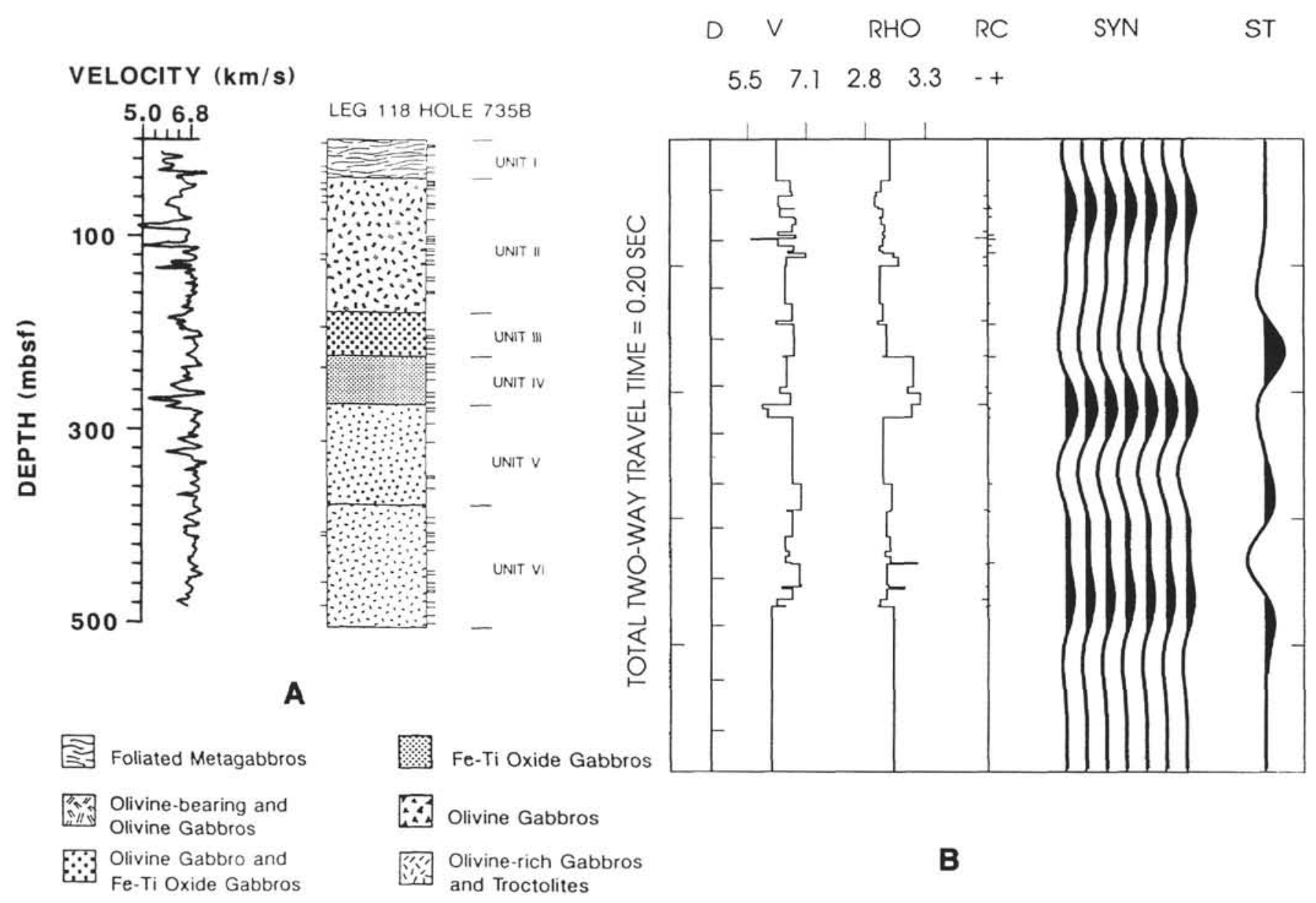

Figure 1. A. Plot of logging velocities obtained with the MCS tool (Robinson, Von Herzen, et al., 1989) at shallow crustal depths vs. the stratigraphy of Hole 735B. Tic marks on the left (vertical cores) and right (horizontal cores) of the stratigraphic column represent the approximate locations of samples used for laboratory measurements. B. Synthetic reflection seismogram calculation using 43 layers identified from observations and visual core descriptions of Hole 735B. Laboratory velocity ( $10 \mathrm{MPa})$ and density measurements obtained from each layer were used along with a Ricker wavelet of $25 \mathrm{~Hz}$ for the construction of the seismogram. The trace labeled " $\mathrm{D}$ " is the depth scale in 50 -m intervals; "V" is the velocity $(\mathrm{km} / \mathrm{s})$; "RHO" is the density model $\left(\mathrm{g} / \mathrm{cm}^{3}\right)$; "RC" is the reflection coefficient series; "SYN" is the synthetic seismogram consisting of seven identical traces; and "ST" is a standard trace consisting of a $+0.1 /-0.1$ reflection coefficient interface that is provided for comparing amplitudes.

$25-\mathrm{Hz}$ source in a medium having an average velocity of 6.70 $\mathrm{km} / \mathrm{s}$ is $268 \mathrm{~m}$. In Figures 1 through 3 , the synthetic seismograms display velocity- and density-depth models, the reflection coefficient series, seven traces showing the reflective response of the hole, and a reference trace representing the seismic response between a typical lower oceanic crust and upper mantle (densities $=3.00$ and $3.30 \mathrm{~g} / \mathrm{cm}^{3}$; velocities $=$ 7.30 and $8.10 \mathrm{~km} / \mathrm{s}$ ) contact with a reflection coefficient of magnitude 0.1. Parameters used in these models are presented in Table 1.

When calculating the synthetic seismograms using onedimensional modeling, we assumed that our layered model persisted laterally over distances on the order of a Fresnel zone. This idea has been assumed in previous calculations of lower crustal reflectivity (Hale et al., 1982). Field observations of the well-explored Samail ophiolite plutonic section show that some layer sets can be traced along strike in northern Oman for distances of approximately $10 \mathrm{~km}$ (Pallister and Hopson, 1981).

The synthetic seismograms calculated for the drilled sequence display a series of significant reflections within Hole 735B. At $10 \mathrm{MPa}$ (Fig. 1B), which approximates in-situ pressures, the reflections observed throughout the first 150 mbsf originate from interlayering of the foliated metagabbros with olivine-bearing gabbros of Unit II. The acoustic impedance contrast necessary to produce the reflections is provided by the low compressional-wave velocities of some of the altered mylonites and foliated metagabbros in contact with undeformed gabbros. At an approximate depth of $250 \mathrm{mbsf}$, the synthetic seismograms show the reflective signature of the Unit IV/Unit V boundary. The acoustic impedance contrast between high-density $\left(\sim 3.20 \mathrm{~g} / \mathrm{cm}^{3}\right)$, low-velocity $(6.75 \mathrm{~km} / \mathrm{s})$ $\mathrm{Fe}-\mathrm{Ti}$ oxide gabbros and brecciated and mylonitic metagabbros at the top of Unit $\mathrm{V}$ produces a large amplitude peak. Beneath, weaker reflections that originate from the interlayering of olivine gabbros, troctolites, and metagabbros in Units $\mathrm{V}$ and VI, occur at depths of 350 to $450 \mathrm{mbsf}$. Low velocities of mylonites and metagabbros having $\mathrm{Fe}-\mathrm{Ti}$ enrichments provide the necessary impedance contrasts to account for the observed low-amplitude peaks in these units.

The synthetic seismograms calculated at higher confining pressures provide information about the reflectivity of the gabbro section at greater depths and can be used for comparison with earlier studies of the lower crustal reflectivity 


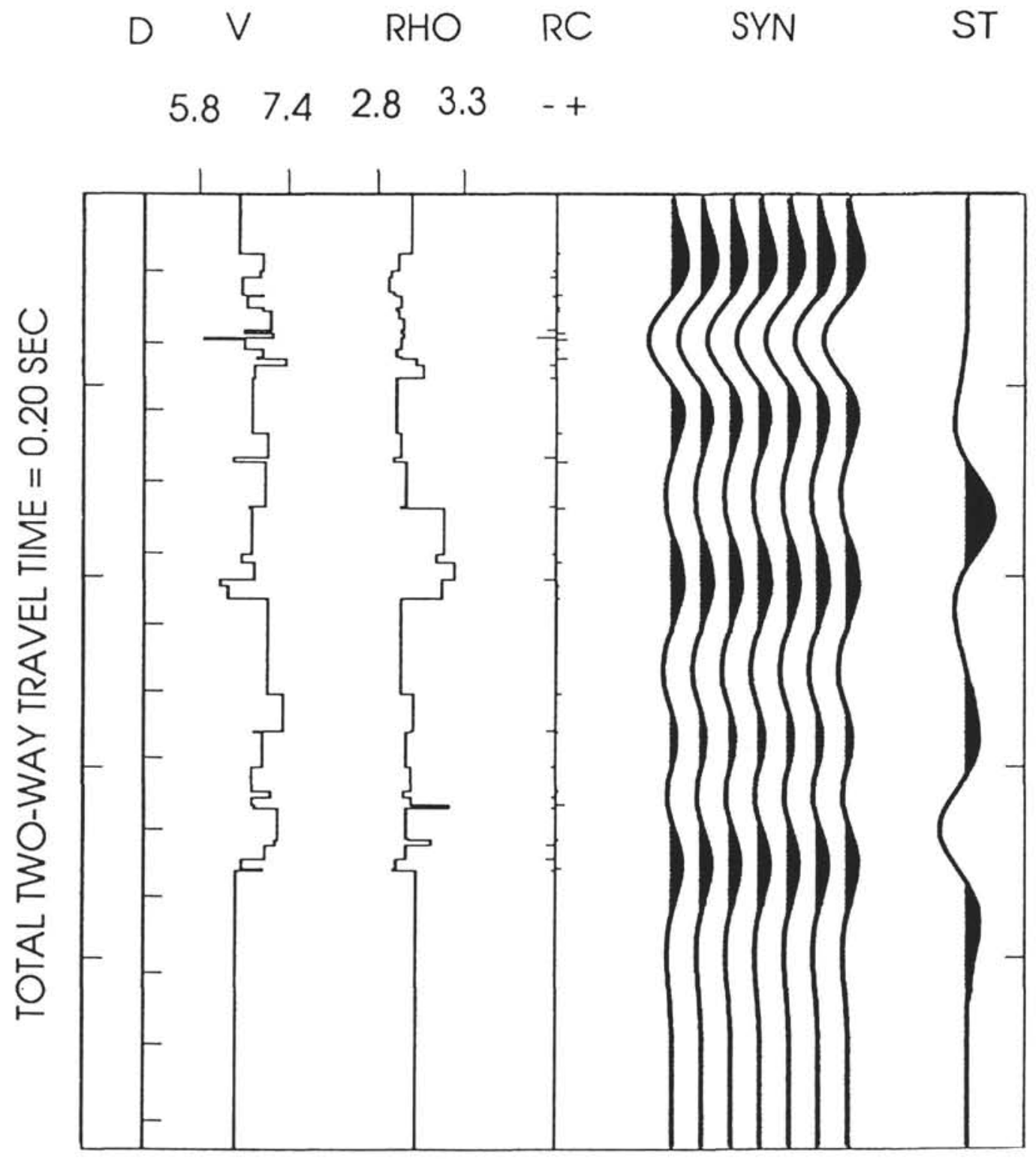

Figure 2. Synthetic seismogram constructed with a $25-\mathrm{Hz}$ Ricker wavelet and velocity measurements at 100 $\mathrm{MPa}$. Higher amplitude caused by the closure of cracks. For details of plot structure refer to Figure 1 .

(McCarthy et al., 1988). Figures 2 and 3, calculated at 100 and $200 \mathrm{MPa}$ respectively, encompass the range of pressures normally found in oceanic layer 3. Although the general patterns of the seismograms are similar, some differences were observed. An increase in the amplitude of the reflections with increasing pressure is attributable to a decrease in crack porosity that produces significant changes in the reflection coefficients. In addition, variations in acoustic impedance contrasts and interference effects within the deformed layers of the lower units create slightly different reflective patterns at different pressures.

\section{PROPERTIES CONTROLLING REFLECTIVITY}

In the previous sections, we showed that at low pressures $(<100 \mathrm{MPa})$, microcracks decrease the reflectivity of the gabbroic rocks at Hole $735 \mathrm{~B}$. At higher pressures, the reflective character of this gabbroic section is primarily controlled by compositional changes and structural features. Other factors that influence the seismic properties in the section are as follows:
1. $\mathrm{SiO}_{2}$ content: Christensen and Szymanski (1988) found an inverse correlation between $V_{p}$ and percentage of $\mathrm{SiO}_{2}$ for a suite of mylonites from the Brevard fault zone of the Southern Appalachians. A similar relationship for the gabbros of Hole 735B was observed (Fig. 4). Chemical analyses (Robinson, Von Herzen, et al., 1989) were obtained from cores taken within $50 \mathrm{~cm}$ of the samples used to determine velocity. Some of the scatter along the best-fitted leastsquares line is perhaps because both measurements were not taken at identical intervals. A correlation of both parameters as a function of depth produces the same inverse relationship for most of the core section of Hole 735B (Fig. 5). In this figure, the spacings between velocity measurements and chemical analyses were less than $2.0 \mathrm{~m}$.

2. $\mathrm{Fe}_{2} \mathrm{O}_{3}$ content: in Figure 5, the region between 200 and $300 \mathrm{~m}$ as well as several sections below 300 mbsf display a different velocity vs. chemical composition relationship. In these cases, $V_{p}$ decreases with decreasing $\mathrm{SiO}_{2}$ content. The discrepancy is attributed to the presence of $\mathrm{Fe}$ - Ti oxides 


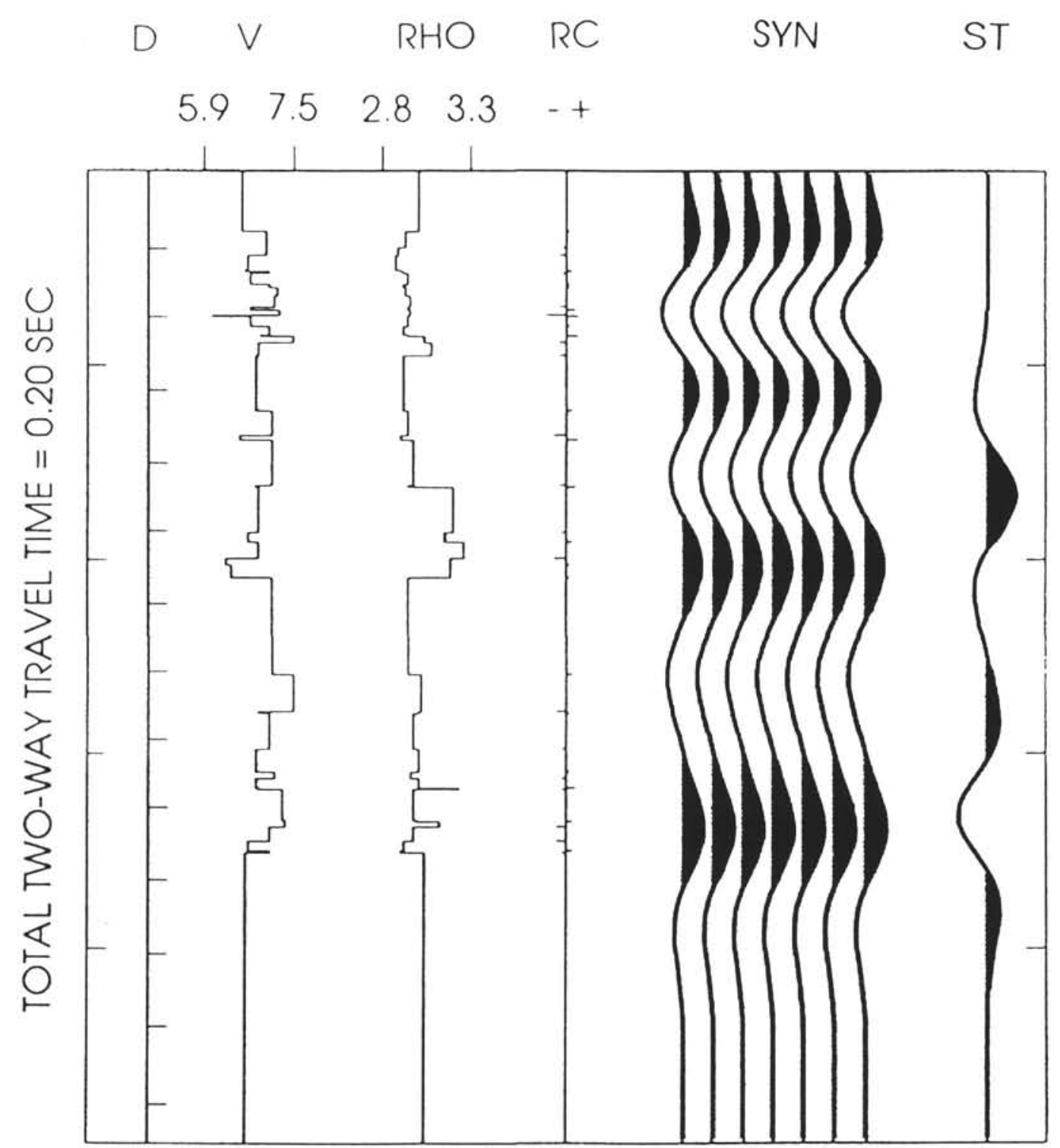

Figure 3. Synthetic seismogram constructed with a $25-\mathrm{Hz}$ Ricker wavelet and velocity measurements at 200 $\mathrm{MPa}$. The high-amplitude reflections are primarily caused by compositional changes that produced acoustic impedance contrasts between layers. For details of plot structure, refer to Figure 1.

within the gabbros and is consistent with the findings of Birch (1961), which showed that iron-rich rocks have relatively low seismic velocities. A plot of compressional-wave velocities as a function of total iron, expressed as a percentage of $\mathrm{Fe}_{2} \mathrm{O}_{3}$ (Fig. 6) for samples from this region, clearly demonstrates the inverse relationship between the two variables. Hence, the chemical variability of the gabbro section produces significant contrasts in velocity and density that are probably responsible for some of the variations in reflectivity observed in the seismograms in Figures 2 and 3.

3. Mineral orientation: another factor for consideration when studying the reflectivity of the gabbroic sequence at Hole $735 \mathrm{~B}$ is the role of preferred mineral orientation in producing reflections. Iturrino et al. (this volume) show that preferred orientation of both plagioclase and amphibole within mylonites and metagabbros produces significant velocity anisotropy. Some of the observed reflections might originate from acoustic-impedance contrasts caused by vertical varia- tions in anisotropy within sections having relatively uniform bulk compositions.

To examine the effect of mineral orientation on the reflectivity of this gabbroic section, synthetic seismograms for two trial models were calculated (Fig. 7). Both models are characterized by alternating isotropic and anisotropic layers having an approximate layer thickness of $30 \mathrm{~m}$. In the first model, the anisotropy is generated by the preferred orientation of plagioclase that is distributed with the fast-velocity direction oriented vertically (Iturrino et al., this volume). In the second model, anisotropy is controlled by amphibole orientation (i.e., slow normal incidence) and the same specifications as the previous model. The first isotropic/anisotropic interface has a velocity contrast equal to $5 \%$ of the maximum azimuthal velocity variation; for each of the succeeding boundaries, the velocity contrast resulting from anisotropy increases by $5 \%$ until it reaches a maximum of $15 \%$. This sequence is then repeated for a total depth of $400 \mathrm{~m}$. The selection of this range 
Table 1. Parameters used for calculating the synthetic seismograms of Hole 735B.

\begin{tabular}{lr}
\hline Number of points per trace & 200.0000 \\
Sampling interval (s) & 0.0010 \\
Interval for the depth scale (km) & 0.0500 \\
Length of distance axis of plot (in.) & 5.0000 \\
Beginning time & 0.0000 \\
Ending time & 0.1750 \\
Length of time axis of plot (in.) & 5.0000 \\
Number of intervals on time axis & 5.0000 \\
Frequency of Ricker wavelet (Hz) & 25.0000 \\
Number of extremes in Ricker wavelet & 3.0000 \\
Number of points on wavelet to taper & 0.0000 \\
Automatic Gain Control applied & No \\
Length of the window in points of & 400.0000 \\
seismogram & \\
Amplitude scale factor & 3.0000 \\
\hline
\end{tabular}

was based on earlier observations of velocity anisotropy within the drill core (Robinson, Von Herzen, et al., 1989; Iturrino et al., this volume) that originated from preferred mineral orientation. Therefore, the maximum anisotropy of $15 \%$ represents a realistic upper limit for the amount of mineral orientation that can be present within the rock samples drilled at the Atlantis II Fracture Zone. Densities remained constant throughout these models and were used with calculated velocities to determine the reflection coefficients for the several interfaces.

Models having increasing plagioclase and amphibole orientations show that strong reflections can originate from layers having $V_{p}$ anisotropy greater than $10 \%$. These results suggest that a well-defined fabric is required to produce reflections by preferred mineral orientation. We postulate that the reflectivity of the gabbroic sequence drilled at the Atlantis II Fracture Zone originated mainly from variations in chemical composition; however, because the $V_{p}$ anisotropy over much of the core section recovered from Hole $735 \mathrm{~B}$ is $5 \%$ to $10 \%$ (S. Kirby et al., unpublished data), anistropy may produce significant reflections. These observations are in agreement with earlier studies of the North Atlantic (McCarthy et al., 1988), where strong lower crustal reflections are attributed to the effects of compositional layering and perhaps some mylonitization.

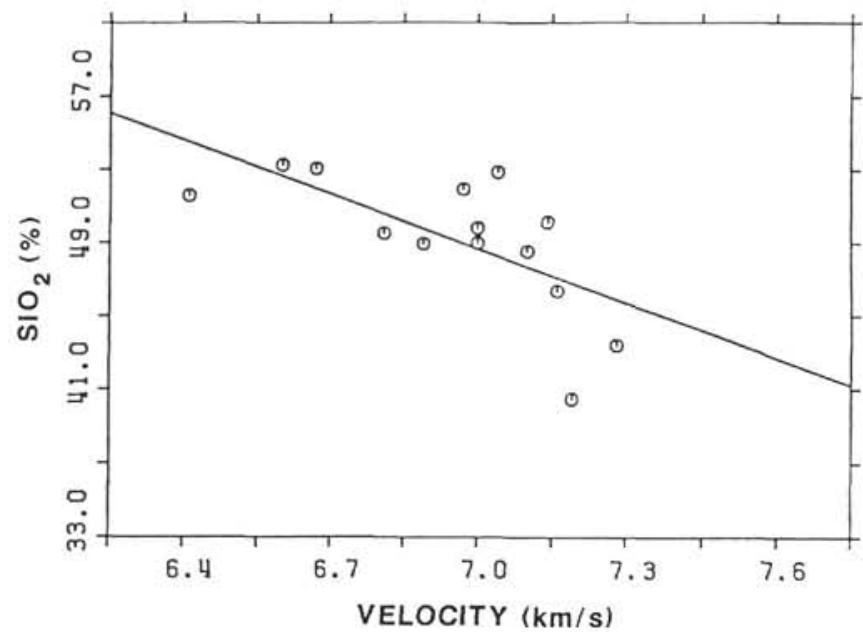

Figure 4. Variation of compressional-wave velocities with $\mathrm{SiO}_{2}$ content measured on the drill core from Hole 735B (Robinson, Von Herzen, et al., 1989). Chemical analysis was performed within $50 \mathrm{~cm}$ or less from the samples used for velocity measurements. Solid line represents least-squares solution.
$\mathrm{Vp}(\mathrm{km} / \mathrm{s})$

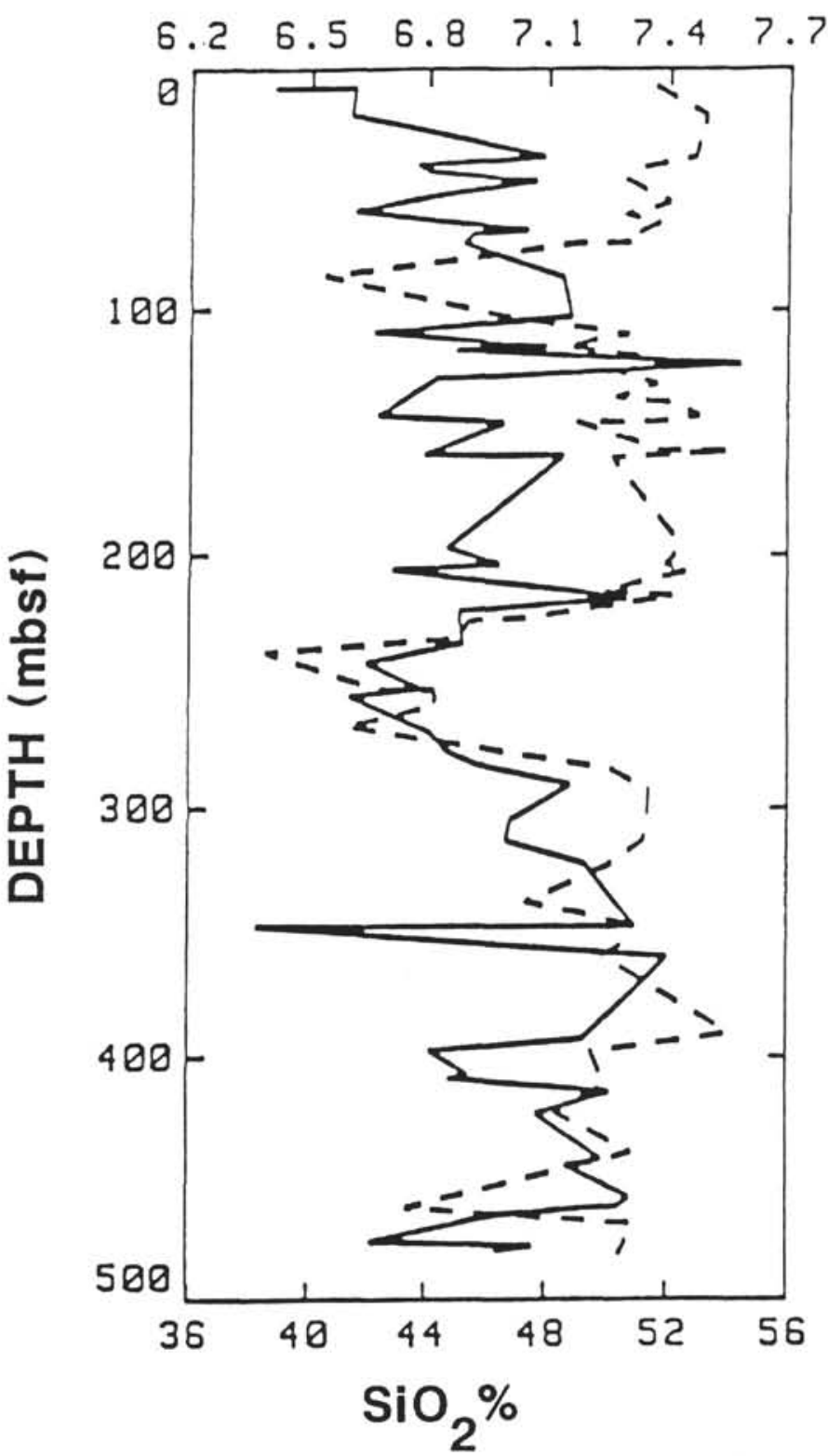

Figure 5. Correlation of percentage of $\mathrm{SiO}_{2}$ (dashed line) and compressional-wave velocities (solid line) with depth. Diagram shows a general inverse relationship between both parameters for most of the hole, except for a distinct region between 200 and $300 \mathrm{mbsf}$ and several sections below 300 mbsf. Chemical data were obtained from shipboard analyses during Leg 118.

\section{SUMMARY}

Synthetic seismograms (constructed with laboratory-measured velocities and densities) reveal the following conclusions about the reflectivity of the gabbroic sequence drilled at Hole 735B:

1. Microcrack porosity influences the amplitude of reflections at low pressures, while at higher pressures, variations in chemical composition are more important.

2. High percentages of $\mathrm{SiO}_{2}$ as well as $\mathrm{Fe}_{2} \mathrm{O}_{3}$ produce low compressional-wave velocities. Variations in silica and iron 


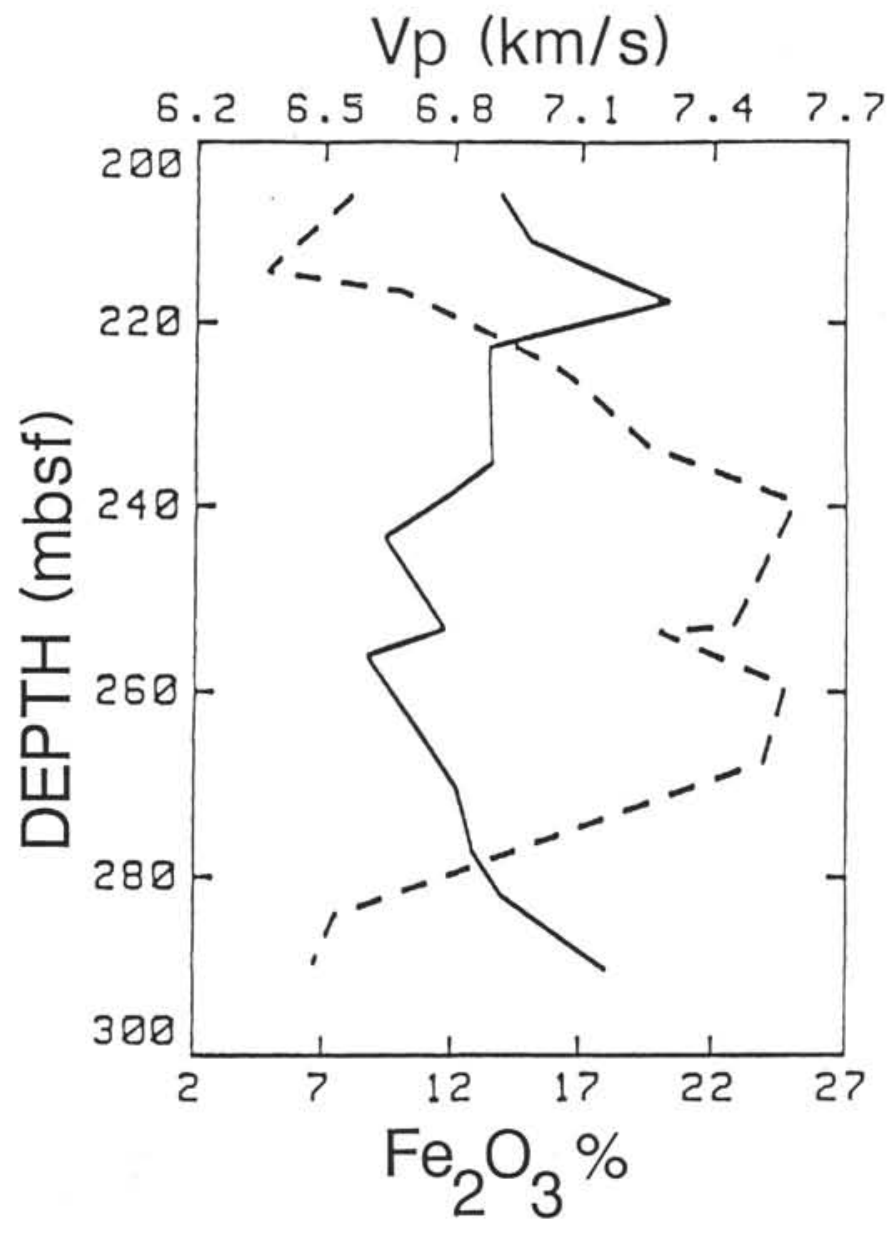

Figure 6. Decrease of compressional-wave velocities with increasing $\mathrm{Fe}_{2} \mathrm{O}_{3}$ content for the region between 200 and 300 mbsf. Solid lines represent velocities, and dashed lines represent iron content.

are responsible for contrasts in acoustic impedance that generate observed reflections.

3. Preferred mineral orientations of plagioclase and amphibole can produce reflections from chemically homogeneous regions, if sufficient anisotropy is present and anisotropic sections alternate with isotropic layers. Strong reflections are produced when anisotropy is greater than $10 \%$.

\section{ACKNOWLEDGMENTS}

G. Iturrino expresses his gratitude to W. Wepfer, D. Szymanski, and D. Helgeson for their assistance with computer programming and to $\mathrm{R}$. Von Herzen as well as two unknown reviewers for their helpful critical comments that improved the manuscript. G. Soto helped with the preparation of this manuscript. The authors also thank JOI-USSAC and the Office of Naval Research (ONR) Contract No. N0001489-J-1209 for their financial support.

\section{REFERENCES}

Birch, F., 1960. The velocity of compressional waves in rocks to 10 kilobars, Part 1. J. Geophys. Res., 65:1083-1102.

1961. The velocity of compressional waves in rocks to 10 kilobars, Part 2. J. Geophys. Res., 66:2199-2224.

Christensen, N. I., 1965. Compressional-wave velocities in metamorphic rocks at pressures to 10 kilobars. J. Geophys. Res., 70:61476164.

1985. Measurements of Dynamic Properties of Rocks at Elevated Temperatures and Pressures: Philadephia (Am. Soc. for Testing and Materials), 93-107.

Christensen, N. 1., and Salisbury, M. H., 1975. Structure and constitution of the lower oceanic crust. Rev. Geophys. Space Phys., 13:57-86. Christensen, N. I., and Szymanski, D. L., 1988. Origin of reflections from the Brevard fault zone. J. Geophys. Res., 93:1087-1102.

Ewing, J., and Ewing, M., 1959. Seismic refraction measurements in the Atlantic Ocean basins, in the Mediterranean Sea, on the Mid-Atlantic Ridge, and in the Norwegian Sea. Bull. Geol. Soc. Am., 70:291-318.

Hale, L. D., Morton, C. J., and Sleep, N. H., 1982. Reinterpretation of seismic reflection data over the East Pacific Rise. J. Geophys. Res., 87:7707-7717.

Hess, H. H., 1962. History of ocean basins. Geol. Soc. Am., Buddington Vol., 599-620.

Houtz, R., and Ewing, J., 1976. Upper crustal structure as a function of plate age. J. Geophys. Res., 81:2490-2498.

Hyndman, R. D., and Drury, M. J., 1976. The physical properties of oceanic basement rocks from deep sea drilling on the Mid-Atlantic Ridge. J. Geophys. Res., 81:4042-4059.

Le Pichon, X., Houtz, R. E., Drake, C. L., and Nafe, J. E., 1965. Crustal structure of the mid-ocean ridges: seismic refraction measurements. J. Geophys. Res., 70(2):319-339.

McCarthy, J., Mutter, J. C., Morton, J. L., Sleep, N. H., and Thompson, G. A., 1988. Relic magma chamber structures preserved within Mesozoic North Atlantic crust?. Geol. Soc. Am. Bull., 100:1423-1436.

Pallister, J. S., and Hopson, C. A., 1981. Samail ophiolite plutonic suite: field relations, phase variation, cryptic variation and layering, and a model of a spreading ridge magma chamber. J. Geophys. Res., 86:2593-2644.

Raitt, R. W., 1956. Seismic refraction studies of the Pacific Ocean basin. Bull. Geol. Soc. Am., 67:1623-1640.

Ricker, N., 1953. The form and laws of propagation of seismic wavelets. Geophysics, 18:10-40.

Robinson, E. A., and Treitel, S., 1977. The fine structure of the normal incidence synthetic seismogram. Geophys. J. Royal Astron. Soc., 53:289-309.

Robinson, P. T., Von Herzen, R. P., et al., 1989. Proc. ODP, Init. Repts., 118: College Station, TX (Ocean Drilling Program).

Shor, G. G., Menard, H. W., and Raitt, R. W., 1969. Regional observations: the structure of the Pacific Basin. In Maxwell, A. E. (Ed.), The Sea, Vol. 4: New York (Wiley), 3-27.

Talwani, M., Le Pichon, X., and Ewing, M., 1965. Crustal structure of the mid-ocean ridges: computed model from gravity and seismic refraction data. J. Geophys. Res., 70(2):341-352.

Date of initial receipt: 7 August 1989

Date of acceptance: 4 June 1990

Ms 118B-152 

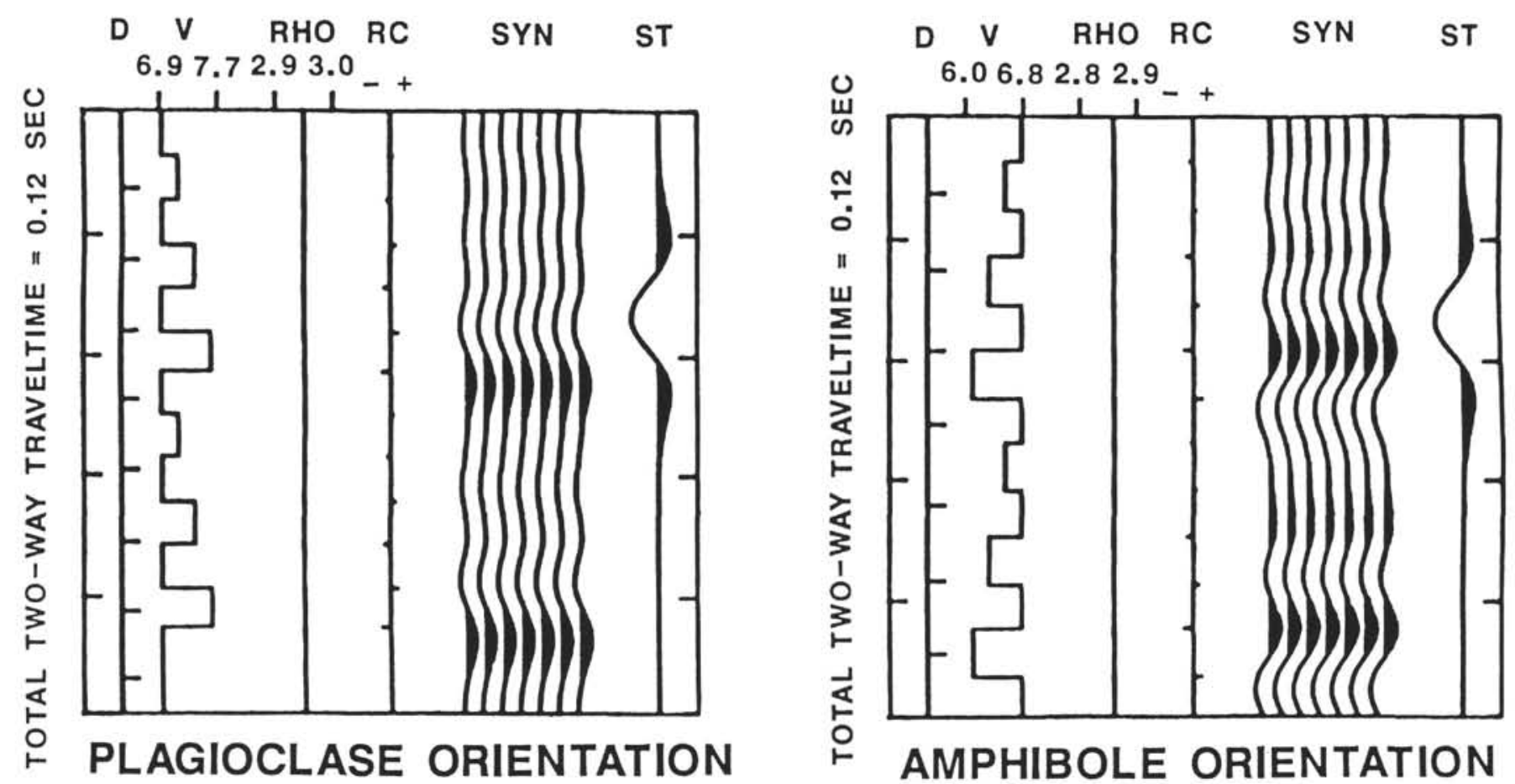

Figure 7. Synthetic seismogram calculated to determine the contribution of both plagioclase (fast vertical incidence) and amphibole orientation (slow vertical incidence) to the reflectivity of Hole 735B. Variations in anisotropy for both models range from 5\% to $15 \%$. For details of plot structure, refer to Figure 1 caption and text. 